\title{
Editorial
}

\section{E-Government Trends and Country Profiles Highlight Waseda Rankings}

The anticipated focus among industrial as well as many developing countries on providing "citizencentric services" is well documented in the 2009 Waseda University International e-Government Rankings. We appreciate the cooperation and assistance of Prof. Dr. Toshio Obi, Director of the Institute of EGovernment and his research team in making it possible for I-Ways to publish the full research report as a Special Issue. Report will be especially valuable to those involved or conducting research on aspects of e-Governance because it presents a number of benchmark indicators that will facilitate interpreting the rankings. The profiles e-Government development in 34 countries and jurisdictions based on the benchmarking methodology, should be useful to both e-Government researchers and practitioners.

In addition to examining the main trends using several key indicators, the report contains a number of practical recommendations. The importance of network preparedness, user-friendly and secure electronic services, uniform and integrated management of ICT, a well designed home pages, appointment and responsibilities of Chief Information Officers (CIOs), as well as e-Government promotional activities, are the main criteria measuring e-Government leadership.

Among the key recommendations presented in the Waseda Rankings is extending e-Government services to regional and municipal levels of government and the need for organizational transformation involving leadership as well as technical operations, for e-Government to achieve maximum benefits and bring maximum efficiencies there must be greater eGovernment promotion so that much greater citizens and businesses take full advantages of efficiencies offered by e-Services.

The 10 top-ranked jurisdictions were almost predictable using Waseda's Rankings criteria. By evaluating e-Government services on the basis of a practical set of key indicators, the results both demonstrate the practicality of this methodology and reward governments for moving from theory into very pragmatic practices. 